\title{
Effect of road transportation on the serum biochemical parameters of cynomolgus monkeys and beagle dogs
}

\author{
Takehiro OCHI ${ }^{1)^{*}}$, Azusa YAMADA ${ }^{2)}$, Yuki NAGANUMA ${ }^{1)}$, Noriko NISHINA ${ }^{3)}$ and Hironari KOYAMA ${ }^{1,2)}$ \\ 1)Laboratory Animal Science Div., Astellas Research Technologies Co., Ltd., 1-6, Kashima 2-chome, Yodogawa-ku, Osaka 532-8514, \\ Japan \\ ${ }^{2)}$ Laboratory Animal Science Div., Astellas Research Technologies Co., Ltd., 21, Miyukigaoka, Tsukuba, Ibaraki 305-8585, Japan \\ 3)Drug Safety Research Labs., Astellas Pharma Inc., 1-6, Kashima 2-chome, Yodogawa-ku, Osaka 532-8514, Japan
}

(Received 28 August 2015/Accepted 19 January 2016/Published online in J-STAGE 1 February 2016)

ABSTRACT. To determine the effect of long-distance (approximately $600 \mathrm{~km}$ ) road transportation on the blood biochemistry of laboratory animals, we investigated the changes in serum biochemical parameters in healthy cynomolgus monkeys and beagle dogs transported by truck from Osaka to Tsukuba, Japan. The concentrations of serum cortisol, total bilirubin and aspartate aminotransferase in monkeys increased during transportation. Serum cortisol and total bilirubin levels in dogs also increased during transportation, but serum triglyceride decreased. Serum parameter values in truck-transported monkeys and dogs returned to baseline levels within two weeks following arrival. Taken together, these results suggest that a two-week acclimation period is the minimum duration required for adaptation following road transportation.

KEY WORDS: acclimation period, blood parameter, canine, monkey, transportation

doi: 10.1292/jvms.15-0502; J. Vet. Med. Sci. 78(5): 889-893, 2016

To reduce costs in pharmacokinetic studies for drug development, laboratory animals, such as cynomolgus monkeys and beagle dogs, are used multiple experiments over prolonged periods at multiple sites, which necessarily requires transport between facilities. Transportation unavoidably induces stress in laboratory animals [15], in turn resulting in physiological, biochemical and behavioral alterations, the effects of which last beyond arrival at their destination $[7,11,20]$. Alleviating this stress and ameliorating any transport-related changes require a period of acclimation [14]. However, the appropriate duration of such acclimation period is unclear.

Here, to improve animal welfare, we assessed associated serum parameter changes in two different types of laboratory animals subject to the same transportation conditions to determine their optimal acclimation periods.

All animal experimental procedures used in this study were reviewed and approved by the Institutional Animal Care and Use Committee of Astellas Pharma Inc. Astellas Pharma Inc.'s animal facilities have been accredited by the Association for Assessment and Accreditation of Laboratory Animal Care (AAALAC) International.

Nineteen healthy male cynomolgus monkeys, aged 3 to 6 years, were transported by truck from Osaka to Ibaraki, Japan. The housing environments for the cynomolgus mon-

*Correspondence to: Ochi, T., Laboratory Animal Science Div., Astellas Research Technologies Co., Ltd. 1-6, Kashima 2-chome, Yodogawa-ku, Osaka 532-8514, Japan.

e-mail: takehiro.ochi@astellas.com

(C)2016 The Japanese Society of Veterinary Science

This is an open-access article distributed under the terms of the Creative Commons Attribution Non-Commercial No Derivatives (by-nc-nd) License $<$ http://creativecommons.org/licenses/by-nc-nd/4.0/>. keys before and after transportation are detailed in Table 1. Monkeys were housed in compliance with the Guide for the Care and Use of Laboratory Animals [5]. To enrich the animal's environment, music from a local radio station was played from 1:00 PM to 3:00 PM, and monkeys had access to toys, such as dumbbells, monkey shine mirrors and Kongs (Bio-Serv; Frenchtown, NJ, U.S.A.). Before transportation, monkeys were determined to be healthy based on general appearance, activity and a tuberculosis skin test. All monkeys were serologically negative for B virus.

Thirty-one healthy male beagle dogs, aged 19 to 46 months, were transported by truck from Osaka to Ibaraki, Japan. The housing environments for the beagle dogs before and after transportation are detailed in Table 2. The dogs were housed in compliance with the Guide for the Care and Use of Laboratory Animals [5] and had access to toys, such as dumbbells and balls (Bio-Serv).

The departure point was Kashima R\&D Center, Astellas Pharma Inc. in Osaka, Japan, and the destination was Tsukuba Research Center, Astellas Pharma Inc. in Ibaraki, Japan. The animals were transported in transport cages (300 $\times 310 \times 460 \mathrm{~mm}$ for monkeys; and $570 \times 810 \times 585 \mathrm{~mm}$ for dogs) in air-conditioned trucks $\left(23-26^{\circ} \mathrm{C}\right.$ for monkeys; and $18-22^{\circ} \mathrm{C}$ for dogs) for a duration of approximately $22 \mathrm{hr}$ over a distance of approximately $600 \mathrm{~km}$. To prevent vomiting during road transportation, animals were fasted without any food and water. The last feeding time was one day before the transportation. Upon arrival, usual feeding patterns were resumed.

For blood chemistry measurements, a $1.5-\mathrm{m} l$ blood sample was taken from the saphenous or cephalic vein via disposable syringe between 9:00 AM to 3:00 PM before feeding at baseline before departure, at arrival, and at 1 week ( 6 or 7 days) and 2 weeks (14 days) after arrival. The blood samples 
Table 1. Housing conditions for cynomolgus monkeys before and after transportation

\begin{tabular}{lcc}
\hline & Before transportation & After transportation \\
& Kashima R\&D Center & Tsukuba Research Center \\
\hline Cage size & $650 \times 680 \times 1,253 \mathrm{~mm}$ & $640 \times 680 \times 1,300 \mathrm{~mm}$ \\
Light-dark cycle & $12: 12 \mathrm{hr}$ & $12: 12 \mathrm{hr}$ \\
Temperature & $25 \pm 1{ }^{\circ} \mathrm{C}$ & $25 \pm 2^{\circ} \mathrm{C}$ \\
Humidity & $55 \pm 5 \%$ & $55 \pm 10 \%$ \\
Ventilation & $15-20$ changes $/ \mathrm{hr}$ & $10 \mathrm{changes} / \mathrm{hr}$ \\
Illumination & $150-600 \mathrm{lux}$ & $150-600 \mathrm{lux}$ \\
Food & PS-A $100 \mathrm{~g} /$ animal/day (Oriental Yeast Co., Ltd.) & PS-A $100 \mathrm{~g} /$ animal/day (Oriental Yeast Co., Ltd.) \\
Water & Ad libitum & Ad libitum \\
\hline
\end{tabular}

Table 2. Housing conditions for beagle dogs before and after transportation

\begin{tabular}{lcc}
\hline & Before transportation & After transportation \\
& Kashima R\&D Center & Tsukuba Research Center \\
\hline Cage size & $800 \times 900 \times 640 \mathrm{~mm}$ & $900 \times 1,138 \times 1,500 \mathrm{~mm}$ \\
Light-dark cycle & $12: 12 \mathrm{hr}$ & $12: 12 \mathrm{hr}$ \\
Controlled temperature & $23 \pm 1{ }^{\circ} \mathrm{C}$ & $23 \pm 2{ }^{\circ} \mathrm{C}$ \\
Controlled humidity & $55 \pm 5 \%$ & $55 \pm 10 \%$ \\
Ventilation & $15-20$ changes $/ \mathrm{hr}$ & $10 \mathrm{changes} / \mathrm{hr}$ \\
Illumination & $150-600$ lux & $150-600 \mathrm{lux}$ \\
Food & $\mathrm{TC}-1250 \mathrm{~g} /$ animal/day (Oriental Yeast Co., Ltd.) & DS-A $300 \mathrm{~g} /$ animal/day (Oriental Yeast Co., Ltd.) \\
Water & Ad libitum & Ad libitum \\
\hline
\end{tabular}

were collected into plastic tubes without anticoagulants, allowed to clot and centrifuged at 3,000 rpm for $10 \mathrm{~min}$ at $4^{\circ} \mathrm{C}$ to separate serum. The resulting supernatants were then frozen at $-20^{\circ} \mathrm{C}$ until measurement as serum samples. Samples were assayed using the Automatic Analyzer LABOSPECT 006 (Hitachi High-Technologies Corporation; Tokyo, Japan) for blood chemistry measurements, expect for cortisol, serum levels of which were measured by electrochemiluminescence immunoassay.

Results are expressed as mean \pm standard error of the mean (SEM). Statistical significance was analyzed using the paired $t$-test for two groups. The difference between groups was considered statistically significant when $P<0.05$.

All animals were deemed to be in good physical condition before and after transportation from Osaka to Tsukuba, Japan, in this study. With regard to changes in serum levels in cynomolgus monkeys, concentrations of serum biochemical parameters in peripheral blood taken before and after transportation are shown in Table 3. Serum cortisol levels significantly increased from $32.6 \pm 1.8 \mu \mathrm{g} / \mathrm{d} l$ before transportation to $65.9 \pm 3.1 \mu \mathrm{g} / \mathrm{d} l$ immediately upon arrival $(+102 \%)$. Serum total bilirubin (T.BIL) and aspartate aminotransferase (AST) levels were higher at arrival than before transportation, with significant increases of $+80 \%$ and $+94 \%$, respectively. In contrast, no marked changes were noted in levels of other serum biochemical parameters tested, including total protein (T.P.), albumin (ALB), cholesterol (CHOL), triglyceride (TRIG), alkaline phosphatase (ALP), alanine aminotransferase (ALT), glucose (GLU), blood urea nitrogen (BUN) and creatinine (CREA).

Similar to observations in monkeys, serum cortisol and T.BIL levels were also higher at arrival than before $(+69 \%$ and $+78 \%$, respectively) in beagle dogs (Table 4 ). However, serum TRIG levels were reduced at arrival compared with before $(-44 \%)$. No marked changes were noted in the levels of other serum biochemical parameters (T.P., ALB, CHOL, ALP, AST, ALT, GLU, BUN and CREA).

As shown in Fig. 1a and 1d, serum cortisol levels were markedly higher in both monkeys and dogs on the day of arrival than before transportation and returned to approximately baseline levels by one week after arrival for monkeys and by two weeks after for dogs. Similar to observations with cortisol, the elevated serum T.BIL levels in transported monkeys and dogs returned to approximately baseline levels by one week following arrival (Fig. $1 \mathrm{~b}$ and 1e). The increased serum AST levels in transported monkeys returned to baseline by two weeks following arrival (Fig. 1c), as did the decreased serum TRIG levels in transported dogs (Fig. 1f).

We investigated the effect of transportation on blood chemistry in laboratory animals. The transport process is stressful for animals, which show markedly increased blood cortisol levels $[6,16,17,19]$. Cortisol secreted by adrenal glands via the hypothalamic-pituitary-adrenocortical axis system under stress is a major biochemical indicator of transport stress in several species [13]. In the present study, serum cortisol levels in healthy monkeys and dogs demonstratively increased post-transport. These findings were consistent with those reported elsewhere in the literature $[3,9,10]$ and indicate that road transportation from Osaka to Tsukuba in Japan $(600 \mathrm{~km} ; 22 \mathrm{hr})$ is stressful for both monkeys and dogs. A period of acclimation is crucial for ensuring the welfare of laboratory animals following a lengthy transportation by truck.

While cortisol has been studied extensively, little attention 
Table 3. Concentrations of serum parameters in peripheral blood of cynomolgus monkeys before and after transportation

\begin{tabular}{lcc}
\hline & Before transportation & After transportation \\
\hline Cortisol $(\mu \mathrm{g} / \mathrm{d} l)$ & $32.6 \pm 1.8$ & $\left.65.9 \pm 3.1^{\mathrm{a}}\right)$ \\
Total protein $(\mathrm{g} / \mathrm{d} l)$ & $7.3 \pm 0.1$ & $7.6 \pm 0.1$ \\
Albumin $(\mathrm{g} / \mathrm{d} l)$ & $4.5 \pm 0.1$ & $4.6 \pm 0.1$ \\
Total bilirubin $(\mathrm{mg} / \mathrm{d} l)$ & $0.10 \pm 0.01$ & $\left.0.18 \pm 0.01^{\mathrm{a}}\right)$ \\
Cholesterol $(\mathrm{mg} / \mathrm{d} l)$ & $131 \pm 7$ & $142 \pm 8$ \\
Triglyceride $(\mathrm{mg} / \mathrm{d} l)$ & $28 \pm 2$ & $34 \pm 3$ \\
Alkaline phosphatase $(\mathrm{mU} / \mathrm{m} l)$ & $1,082 \pm 135$ & $1,166 \pm 142$ \\
Aspartate aminotransferase $(\mathrm{mU} / \mathrm{m} l)$ & $34 \pm 2$ & $\left.66 \pm 6^{\mathrm{a}}\right)$ \\
Alanine aminotransferase $(\mathrm{mU} / \mathrm{m} l)$ & $33 \pm 2$ & $42 \pm 3$ \\
Glucose $(\mathrm{mg} / \mathrm{d} l)$ & $67 \pm 2$ & $92 \pm 5$ \\
Blood urea nitrogen $(\mathrm{mg} / \mathrm{d} l)$ & $19 \pm 1$ & $25 \pm 1$ \\
Creatinine $(\mathrm{mg} / \mathrm{d} l)$ & $0.9 \pm 0.05$ & $1.1 \pm 0.06$ \\
\hline
\end{tabular}

Values are means \pm SEM $(\mathrm{n}=19)$. Statistical significance was analyzed using the paired $t$-test for two groups. a) $P<0.01$ indicates a significant difference from the beforetransportation value.

Table 4. Concentrations of serum parameters in peripheral blood of beagle dogs before and after transportation

\begin{tabular}{lcc}
\hline & Before transportation & After transportation \\
\hline Cortisol $(\mu \mathrm{g} / \mathrm{d} l)$ & $1.6 \pm 0.1$ & $2.7 \pm 0.2^{\mathrm{a})}$ \\
Total protein $(\mathrm{g} / \mathrm{d} l)$ & $6.1 \pm 0.1$ & $6.5 \pm 0.1$ \\
Albumin $(\mathrm{g} / \mathrm{d} l)$ & $3.1 \pm 0.04$ & $3.3 \pm 0.04$ \\
Total bilirubin $(\mathrm{mg} / \mathrm{d} l)$ & $0.09 \pm 0.01$ & $0.16 \pm 0.01^{\mathrm{a})}$ \\
Cholesterol $(\mathrm{mg} / \mathrm{d} l)$ & $147 \pm 9$ & $157 \pm 11$ \\
Triglyceride $(\mathrm{mg} / \mathrm{d} l)$ & $43 \pm 5$ & $24 \pm 2^{\mathrm{a}}$ \\
Alkaline phosphatase $(\mathrm{mU} / \mathrm{m} l)$ & $187 \pm 15$ & $183 \pm 14$ \\
Aspartate aminotransferase $(\mathrm{mU} / \mathrm{m} l)$ & $37 \pm 1$ & $33 \pm 1$ \\
Alanine aminotransferase $(\mathrm{mU} / \mathrm{m} l)$ & $40 \pm 2$ & $37 \pm 2$ \\
Glucose $(\mathrm{m} / \mathrm{d} l)$ & $83 \pm 2$ & $89 \pm 1$ \\
Blood urea nitrogen $(\mathrm{mg} / \mathrm{d} l)$ & $12 \pm 0.5$ & $12 \pm 0.4$ \\
Creatinine $(\mathrm{mg} / \mathrm{d} l)$ & $0.6 \pm 0.02$ & $0.6 \pm 0.01$ \\
\hline
\end{tabular}

Values are means $\pm \operatorname{SEM}(\mathrm{n}=31)$. Statistical significance was analyzed using the paired $t$-test for two groups. a) $P<0.01$ indicates a significant difference from the beforetransportation value.

has been focused on the effects of transportation on other serum indicators. In the present study, serum T.BIL levels in both monkeys and dogs were found to be significantly higher post-transport than before. T.BIL is a major intravascular product of heme catabolism from red blood cells induced by oxidative stress [21], and low T.BIL level is associated with incidence of several diseases, such as cardiovascular disease, diabetes and Parkinson's disease [1, 22]. At present, only one study has examined the relationship between T.BIL and transportation of vertebrates, specifically in young calves [12], and data regarding the effects of transportation on laboratory animals in particular are scarce. While our results suggest that T.BIL may act as effectively as cortisol as an indicator of transport stress, why serum T.BIL levels increased following transportation remains unclear. Further research is needed to clarify the role of T.BIL in transported animals.

Serum AST levels in monkeys were significantly increased post-transport in this study. Bejaei et al. reported similar findings, noting a dramatic increase in plasma levels of AST and creatine phosphokinase in ostriches transported for 18 hr [2]. However, serum TRIG levels in dogs were significantly reduced post-transport in this study. We lack definite information on discrepancy between monkeys and dogs in changes in serum parameters, such as AST and TRIG, due to transportation. These factors merit further investigation in future studies.

Given our observations of changes in levels of several serum parameters in laboratory animals following a $600-\mathrm{km}$ road trip with fasting at least $30 \mathrm{hr}$, transported animals should be allowed a period of acclimation following transport before experiment initiation [4]. We therefore additionally assessed the optimum duration of acclimation by measuring changes in levels of stress-related serum parameters at several time points after arrival. Levels of the parameters in question returned to baseline by one to two weeks following arrival. Thus, a period of at least two weeks for acclimation should be allowed before using transported animals, such as 


\section{a) Cortisol in transported monkeys}

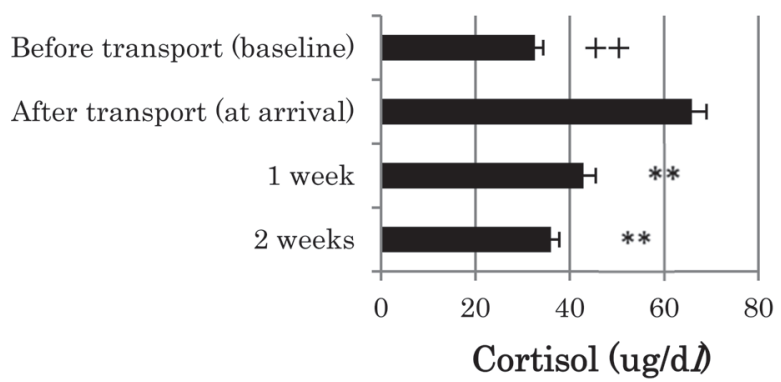

\section{b) T.BIL in transported monkeys}

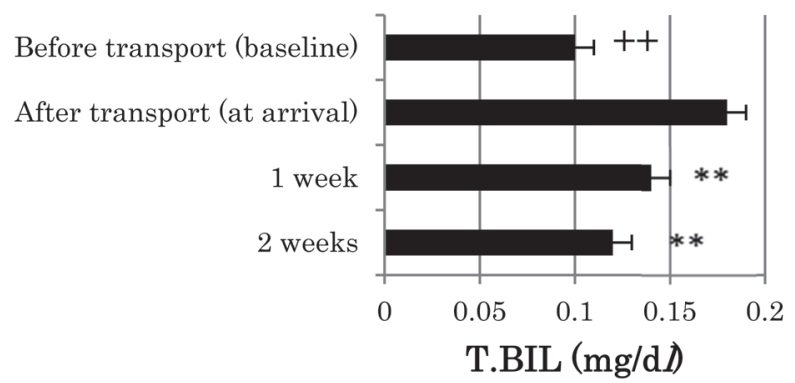

\section{c) AST in transported monkeys}

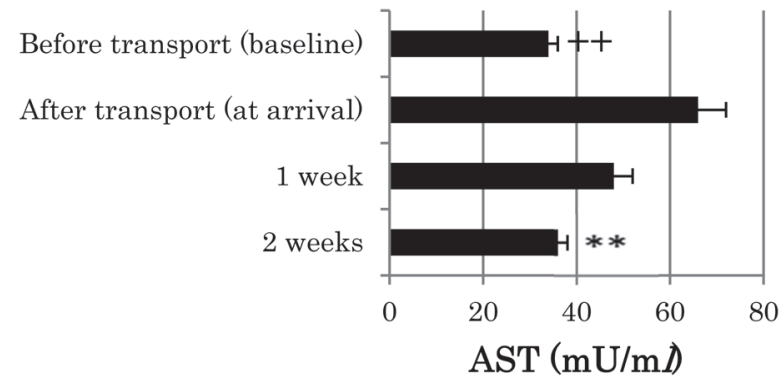

\section{d) Cortisol in transported dogs}

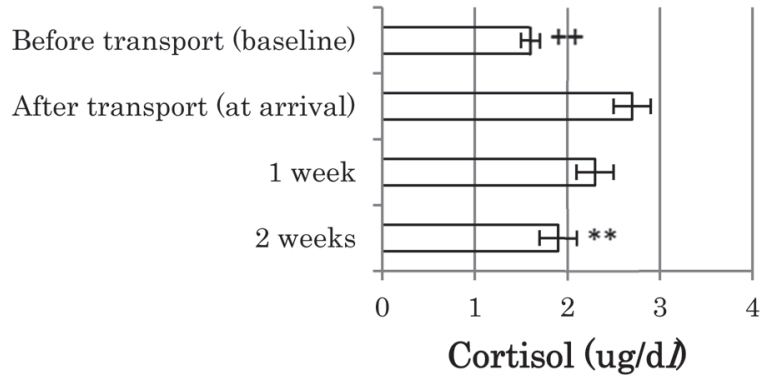

\section{e) T.BIL in transported dogs}

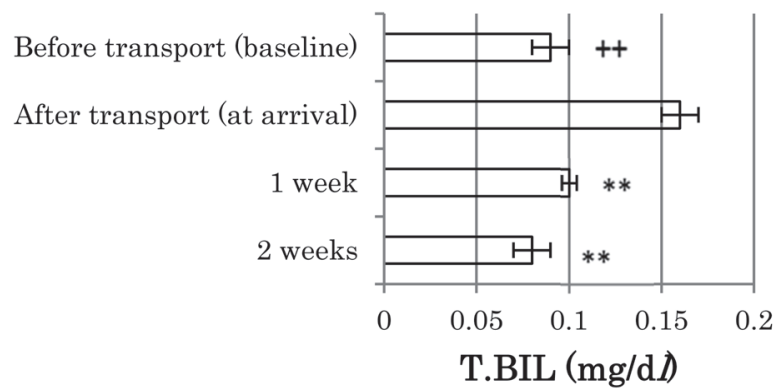

\section{f) TRIG in transported dogs}

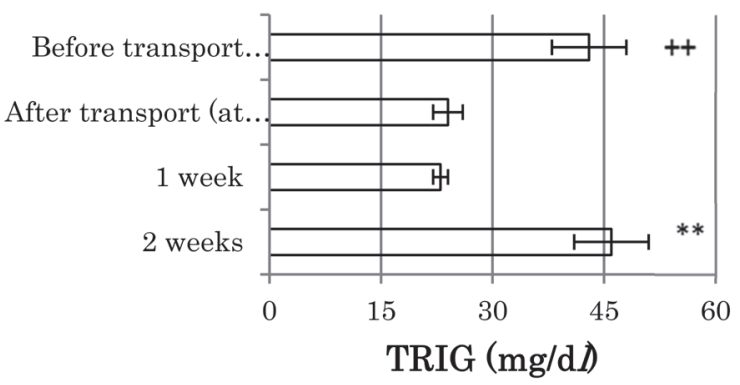

Fig. 1. Changes in serum parameters values after transportation in cynomolgus monkeys and beagle dogs. Values are means \pm SEM. Statistical significance was analyzed using the paired $t$-test for two groups. ${ }^{++} P<0.01$ and $* * P<0.01$ indicate a significant difference from the value obtained immediately following arrival.

monkeys and dogs, in experiments.

Markedly few reports have addressed the effects of transportation and relocation on physiological parameters in laboratory animals, and findings have been conflicting. Kim et al. [9] reported an increase in the neutrophil/lymphocyte ratio and serum cortisol levels in cynomolgus monkeys upon arrival following a 15 -hr trip, and these two indicators returned to baseline 1 week after arrival. Schapiro et al. [18] found that a 21-hr overland transportation and relocation of chimpanzees affected a variety of physiological parameters, with some changes lasting up to 3 months. Honess et al. [8] observed that changes in behavioral patterns in long-tailed macaques caused by transportation did not revert to baseline patterns even 3 weeks after a 58-hr trip by airplane. These discrepancies in findings may depend on the conditions of the transport and relocation.

In conclusion, our results provide useful information regarding adaptation to transportation and relocation in laboratory animals, as changes in serum biochemical parameters following transportation indicate that the transport process is stressful for both monkeys and dogs. A 2-week acclimation period following road-transportation $(600 \mathrm{~km} ; 22 \mathrm{hr})$ was 
found to be sufficient to recover levels of stress-indicating biochemical parameters to baseline in view of animal welfare.

ACKNOWLEDGMENTS. The authors would like to thank Mr. S. Takemoto, Mr. H. Satake and Mr. I. Nishiura for their technical assistance in collecting blood samples.

\section{REFERENCES}

1. Akboga, M. K., Canpolat, U., Sahinarslan, A., Alsancak, Y., Nurkoc, S., Aras, D., Aydogdu, S. and Abaci, A. 2015. Association of serum total bilirubin level with severity of coronary atherosclerosis is linked to systemic inflammation. Atherosclerosis 240: 110-114. [Medline] [CrossRef]

2. Bejaei, M., Bennett, D. C., Schaefer, A. L. and Cheng, K. M. 2014. Effects of pre-transport nutrient supplementation and transport duration on the post-transport blood biochemistry, bodyweight and welfare of ostriches. Anim. Welf. 23: 209-217. [CrossRef]

3. Bergeron, R., Scott, S. L., Émond, J. P., Mercier, F., Cook, N. J. and Schaefer, A. L. 2002. Physiology and behavior of dogs during air transport. Can. J. Vet. Res. 66: 211-216. [Medline]

4. Capitanio, J. P., Kyes, R. C. and Fairbanks, L. A. 2006. Considerations in the selection and conditioning of Old World monkeys for laboratory research: animals from domestic sources. ILAR J. 47: 294-306. [Medline] [CrossRef]

5. Committee for the Update of the Guide for the Care and Use of Laboratory Animals and Institute for Laboratory Animal Research 2010. Environment, housing, and management. pp.41103. In: Guide for the Care and Use of Laboratory Animals, 8th ed. The National Academies Press, Washington, D.C.

6. Cooke, R. F., Guarnieri Filho, T. A., Cappellozza, B. I. and Bohnert, D. W. 2013. Rest stops during road transport: impacts on performance and acute-phase protein responses of feeder cattle. J. Anim. Sci. 91: 5448-5454. [Medline] [CrossRef]

7. Fernström, A. L., Sutian, W., Royo, F., Westlund, K., Nilsson, T., Carlsson, H. E., Paramastri, Y., Pamungkas, J., Sajuthi, D., Schapiro, S. J. and Hau, J. 2008. Stress in cynomolgus monkeys (Macaca fascicularis) subjected to long-distance transport and simulated transport housing conditions. Stress 11: 467-476. [Medline] [CrossRef]

8. Honess, P. E., Johnson, P. J. and Wolfensohn, S. E. 2004. A study of behavioural responses of non-human primates to air transport and re-housing. Lab. Anim. 38: 119-132. [Medline] [CrossRef]

9. Kim, C. Y., Han, J. S., Suzuki, T. and Han, S. S. 2005. Indirect indicator of transport stress in hematological values in newly acquired cynomolgus monkeys. J. Med. Primatol. 34: 188-192. [Medline] [CrossRef]
10. Kuhn, G., Lichtwald, K., Hardegg, W. and Abel, H. H. 1991. The effect of transportation stress on circulating corticosteroids, enzyme activities and hematological values in laboratory dogs. J. Exp. Anim. Sci. 34: 99-104. [Medline]

11. Landi, M. S., Kreider, J. W., Max Lang, C. and Bullock, L. P. 1982. Effects of shipping on the immune function in mice. Am. J. Vet. Res. 43: 1654-1657. [Medline]

12. Mormede, P., Soissons, J., Bluthe, R. M., Raoult, J., Legarff, G., Levieux, D. and Dantzer, R. 1982. Effect of transportation on blood serum composition, disease incidence, and production traits in young calves. Influence of the journey duration. Ann. Rech. Vet. 13: 369-384. [Medline]

13. Möstl, E. and Palme, R. 2002. Hormones as indicators of stress. Domest. Anim. Endocrinol. 23: 67-74. [Medline] [CrossRef]

14. Obernier, J. A. and Baldwin, R. L. 2006. Establishing an appropriate period of acclimatization following transportation of laboratory animals. ILAR J. 47: 364-369. [Medline] [CrossRef]

15. Sackett, G. P. 1981. Pregnancy outcome following jet transport stress in nonhuman primates. J. Med. Primatol. 10: 149-154. [Medline]

16. Saeb, M., Baghshani, H., Nazifi, S. and Saeb, S. 2010. Physiological response of dromedary camels to road transportation in relation to circulating levels of cortisol, thyroid hormones and some serum biochemical parameters. Trop. Anim. Health Prod. 42: 55-63. [Medline] [CrossRef]

17. Sanhouri, A. A., Jones, R. S. and Dobson, H. 1989. The effect of different types of transportation on plasma cortisol and testosterone concentrations in male goats. Br. Vet. J. 145: 446-450. [Medline] [CrossRef]

18. Schapiro, S. J., Lambeth, S. P., Jacobsen, K. R., Williams, L. E., Nehete, B. N. and Nehete, P. N. 2012. Physiological and welfare consequences of transport, relocation, and acclimatization of chimpanzees (Pan troglodytes). Appl. Anim. Behav. Sci. 137: 183-193. [Medline] [CrossRef]

19. Śmiecińska, K., Denaburski, J. and Sobotka, W. 2011. Slaughter value, meat quality, creatine kinase activity and cortisol levels in the blood serum of growing-finishing pigs slaughtered immediately after transport and after a rest period. Pol. J. Vet. Sci. 14: 47-54. [Medline]

20. van Ruiven, R., Meijer, G. W., Wiersma, A., Baumans, V., van Zutphen, L. F. M. and Ritskes-Hoitinga, J. 1998. The influence of transportation stress on selected nutritional parameters to establish the necessary minimum period for adaptation in rat feeding studies. Lab. Anim. 32: 446-456. [Medline] [CrossRef]

21. Vítek, L. and Ostrow, J. D. 2009. Bilirubin chemistry and metabolism; harmful and protective aspects. Curr. Pharm. Des. 15 2869-2883. [Medline] [CrossRef]

22. Vítek, L. and Schwertner, H. A. 2007. The heme catabolic pathway and its protective effects on oxidative stress-mediated diseases. Adv. Clin. Chem. 43: 1-57. [Medline] [CrossRef] 